\section{Psychological barriers and facilitators of colorectal cancer screening: a French qualitative study}

\author{
Morgiane Bridou,' Colette Aguerre, 1 \\ Guillaume Gimenes, 1 \\ Violaine Kubiszewski,1 Armel Le Gall,2 \\ Catherine Potard, 3 Olivier Sorel, 1 \\ Christian Reveillere ${ }^{1}$ \\ 1Department of Psychology, François \\ Rabelais University, Tours; 2Psychiatric \\ Clinic of Montchenain, Esvres; \\ 3Department of Psychology, Reims \\ Champagne-Ardenne University, Reims, \\ France
}

\section{Abstract}

The aim of this qualitative study was to explore the psychological barriers to and facilitators of undergoing the Hemoccult-II ${ }^{\circledR}$ colorectal cancer screening test in France. Sixty-nine French people aged 50 to 74 years were divided into seven qualitative focus groups. Three issues were discussed with participants: knowledge and beliefs about colorectal cancer screening; facilitators of colorectal cancer screening by Hemoccult-II ${ }^{\circledR}$; barriers to colorectal cancer screening by Hemoccult-II ${ }^{\circledR}$. All the discussions were led by two psychologists and were recorded, transcribed verbatim and analyzed using qualitative data analysis software. Correspondence factor analyses identified three dimensions for each topic. The main psychological facilitators of colorectal cancer screening were: information about colorectal cancer screening, perceived simplicity of using Hemoccult-II ${ }^{\circledR}$, and perception of risk. Uncertainty about the reliability of Hemoccult-II ${ }^{\circledR}$, health anxiety, and embarrassment emerged as the main barriers to colorectal cancer screening. Cross-sectional analyses identified the differences between the views expressed by women and men. Women appeared more embarrassed about Hemoccult-II ${ }^{\circledR}$ and men seemed to be more worried about colorectal cancer. This preliminary study suggests that psychological factors play an important role in colorectal cancer screening by Hemoccult-II ${ }^{\circledR}$. This finding may help health organizations to conceive better awareness campaigns to promote colorectal cancer screening in order to reduce the related mortality rate by taking into account psychological determinants.

\section{Introduction}

Every year, 37,000 new cases of colorectal cancer (CRC) are diagnosed in France, and 17,000 deaths can be directly attributed to this disease. 1 The prevalence of CRC has risen by $8 \%$ in the last 30 years. $^{2}$ At the same time, the survival rate has risen by $15 \%$, thanks largely to better screening. ${ }^{2}$ It is now widely recognized that early diagnosis improves the effectiveness of treatment. ${ }^{3}$ Nevertheless, many cases of CRC are still discovered at an advanced stage, significantly reducing the survival chances of the patients. ${ }^{3}$ This observation has led to the health authorities in many western countries setting up CRC screening programs to detect the disease as early as possible, even before the emergence of visible symptoms. ${ }^{3}$

In France, organized CRC screening began in 2002 in 22 pilot districts, and was extended to the whole country in 2008.4 The screening test that is commonly used in France for people with an average risk of developing CRC is the Hemoccult-II ${ }^{\circledR}$ guaiac test, carried out at home, which tests for occult faecal blood (gFOBT). The rate of participation in the CRC screening program in $2009-2010$ was $34 \%$ (according to the Institut de Veille Sanitaire; Appraisal of the colorectal cancer screening programme, 2011). In spite of repeated and inventive publicity campaigns, the rate of participation remains well below recommended norms, the European standard being a minimum of $45 \%$ (European guidelines for quality assurance in colorectal cancer screening and diagnosis. Data not shown).

Consequently, understanding the factors determining the decision to undergo a CRC screening procedure is a major public health issue. A number of authors have studied the economic, social and psychological barriers to and facilitators of CRC screening, mostly in America, using qualitative methods.

\section{Socioeconomic barriers}

People frequently give lack of time as a reason for not carrying out CRC screening tests. ${ }^{5-7}$ Some people feel torn between apparently contradictory demands, those that give priority to their daily and professional activities on the one hand, and those that encourage them to take care of their health through regular screening tests on the other. ${ }^{8}$

The cost of screening can be a major deterrent for people on low incomes and/or who have no private health insurance.9-12 Difficulty with transport and lack of local health services have also been raised to explain the low rate of participation in screening programs. ${ }^{13}$

\section{Lack of knowledge and erroneous beliefs about colorectal cancer}

For most people, information and knowledge about CRC are clearly rudimentary, patchy or even non-existent.14-16 This manifest lack of knowledge and its potential risks are clearly at
Correspondence: Morgiane Bridou, Université François Rabelais de Tours, UFR Arts et Sciences Humaines, Département de Psychologie, EA 2114 Psychologie des Ages de la Vie, 3 rue des Tanneurs BP 4103, 37041 Tours Cedex 01, France.

Tel. +33.247.366685 - Fax: +33.247 .366484$

E-mail: morgiane.bridou@univ-tours.fr

Key words: psycho-oncology, colorectal cancer screening, health anxiety, embarrassment, risk perception.

Acknowledgements: we would like to thank Dr Ken Haguenoer and Dr Jérôme Viguier of the Centre de Coordination des Dépistages des Cancers d'Indre-et-Loire (Cancer-screening coordination centre of the département of Indre-etLoire) for their support and logistic assistance in carrying out this study, together with Christèle Lartigau and Brigitte Geffray.

Contributions: $\mathrm{MB}$, has conducted the study and wrote this article; GG, VK, ALG, CP, OS, have conducted the focus groups and corrected this article; CA, CR, have coordinated the study and corrected this article.

Conflict of interests: this qualitative study is part of a broader scientific research programme investigating the psychological barriers to and facilitators of the colorectal cancer screening test ("EF-SPEED-CANCOL" study), coordinated by Colette Aguerre and funded by the French National Cancer Institute (INCa, France) following its 2010 call for projects entitled Recherche en sciences humaines et sociales, santé publique et épidémiologie (Human and social sciences research, public health and epidemiology). It was the subject of a doctoral thesis by Morgiane Bridou.

Received for publication: 31 October 2012.

Revision received: 4 January 2013.

Accepted for publication: 4 January 2013.

This work is licensed under a Creative Commons Attribution NonCommercial 3.0 License (CC BYNC 3.0).

(C)Copyright M. Bridou et al., 2013

Licensee PAGEPress, Italy

Health Psychology Research 2013; 1:e22

doi:10.4082/hpr.2013.e22

least partly responsible for low screening rates. ${ }^{8}$ Thus some people consider that CRC cannot be a serious disease, because if it were, they would be better informed. ${ }^{17}$

There are many uncertainties surrounding the factors that increase the risk of CRC. ${ }^{18}$ For example, people are particularly hesitant when asked to identify groups of people at high risk of developing CRC.19,20 Overall, not feeling at risk stops people carrying out a screening test because they do not feel personally concerned, particularly if they consider themselves to be 
in good health,12,21 if they are asymptomatic,22 if they feel too young, ${ }^{11}$ and/or there is no personal and/or family history of CRC. 5

\section{Lack of knowledge and erroneous beliefs about colorectal cancer screening}

CRC screening methods, particularly Hemoccult-II ${ }^{\circledR}$, are relatively unknown by the general public. 7 Some people confuse CRC screening and screening for prostate cancer. ${ }^{17}$ Others seem to be unaware of the need for regular screening, or at least think that once is enough. ${ }^{22}$ The Hemoccult-II ${ }^{\circledR}$ test raises a large number of questions and strong reticence, ${ }^{14}$ which very likely explains why it is the most infrequently used test. ${ }^{20}$ It arouses considerable distrust due to its presumed lack of reliability, based on the feeling that only tests carried out by doctors guarantee a degree of credibility, ${ }^{9}$ together with the fact that certain members of the medical profession question the test's sensitivity. 15,23

However, most people are convinced of the importance of CRC screening. The bestinformed and most compliant people are generally those who have already carried out the test at least once. 14

\section{Drawbacks and advantages of the Hemoccult-II test}

For most people, the Hemoccult-II ${ }^{\circledR}$ test appears to have many drawbacks (food restrictions, handling faeces, loss of time) compared to its perceived use. ${ }^{24}$ It is often seen to be complicated due to the unclear instructions. ${ }^{11,21}$ This leads people to doubt their ability to carry it out well enough for it to be analyzed correctly. ${ }^{23}$ This feeling of inadequacy explains why even the most compliant people admit that they put off doing the test. ${ }^{24}$

However, the Hemoccult-II ${ }^{\circledR}$ test is generally well-accepted in that it has the advantage of being performed in the privacy of the home and that it is neither painful nor invasive, unlike a colonoscopy. 25

\section{Embarrassment and disgust}

The Hemoccult-II ${ }^{\circledR}$ test is often described as being revolting, disgusting and unhealthy, ${ }^{7}$ mainly due to the disgust and embarrassment caused by handling, collecting and storing faeces. ${ }^{7}$ This embarrassment is often given as a reason for refusing to carry out the test. ${ }^{23}$

\section{Anxiety}

Fear of cancer is regularly mentioned in studies. ${ }^{8,23}$ Some of the people interviewed consider that CRC is more serious than other forms of cancer in that it develops more rapidly, is more likely to produce metastases, is more painful,18 and has a higher mortality rate. 17
The fear that the screening test will detect a cancer is commonly expressed, because many people consider a positive test to be a death sentence. 25,26 They consequently adopt an avoidance strategy based on the belief that they are in good health and the feeling that it is sometimes better not to know. ${ }^{12,14}$

\section{Aim of the study}

A number of qualitative studies using focus groups have already been carried out with a variety of populations, notably in the United States, in order to understand the obstacles preventing people from carrying out colorectal cancer screening tests. Surprisingly, to our knowledge there has been no such study in French-speaking countries, with the exception of two studies that focused on the barriers and incentives of CRC screening from the standpoint of general practitioners and specialists. 27,28

The aim of our qualitative exploratory pilot study was thus to identify more precisely the psychological barriers and facilitators regarding CRC screening using Hemoccult-II ${ }^{\circledR}$, through interviews with French people at average risk of developing CRC and who were within the recommended age range for screening.

\section{Materials and Methods}

\section{Participants}

Seven single-sex focus groups were organized with a sample of 69 people ( 38 women and 31 men) living in France. There were three inclusion criteria: i) age 50 or over; ii) no personal history of CRC; iii) good understanding and command of spoken and written French.

Participants were recruited via an article in a French daily newspaper which explained that researchers were looking for volunteers to take part in group meetings about CRC screening. People interested were asked to contact us by telephone or email. All the participants were volunteers and gave their written informed consent.

The mean age of participants was 60.71 years (SD 6.16). The mean age of women was 59.47 years, range $50-72$ (SD 5.60). The mean age of men was 62.22 years, range 51-74 (SD 6.56). A comparative analysis revealed no significant difference between the mean ages of men and women $[\mathrm{F}(1.67)=3.5349, \mathrm{NS}]$.

The majority of participants (94.2\%) lived in an urban environment (Table 1). The majority had no personal history of cancer $(85.5 \%)$ or had a history of another type of cancer (14.5\%). Finally, $58.0 \%$ of participants had a family history of some type of cancer.

When questioned about any previous use of Hemoccult-II ${ }^{\circledR}$ (Table 2), the majority of partic- ipants declared that they had used it at least once $(91.2 \%)$, while the remainder $(8.8 \%)$ said they had never used it. The majority of participants who had already used the Hemoccult-II ${ }^{\circledR}$ test at least once intended to repeat it in the future (86.9\%). Among the participants who had never used the test, the same number expressed their intention to use it (4.3\%) and not to use it (4.3\%) in the future.

\section{Materials}

A chart was drawn up for the focus group interviews, giving details of the organisation of the interviews and the topics to be raised in the form of open-ended questions (Table 3 ).

The seven focus groups were held in a meeting room of the François Rabelais University of Tours (France), equipped with a computer and a video-projector. The interviews were recorded in their entirety using a digital dictaphone. The following aids were used to encourage the participants to express their opinions: a 30 second film promoting CRC screening was shown and discussed by the participants, and an instruction leaflet for using the HemoccultII ${ }^{\circledR}$ test was handed out and read by the participants. [This 30-second advertisement for colorectal cancer screening, entitled Le voyage intérieur, was first televised from $13^{\text {th }}$ September to $14^{\text {th }}$ October 2008 , and repeated from 1st to 21st March 2010. It describes a journey inside the human body, ending with a view of a polyp, represented in a non-threatening and undramatic manner with the following message: And yet in most cases, if it (colorectal cancer) is detected early enough, it is not bad.]

Tables were arranged in a semicircle so that all the participants could see and interact with each other. A general information sheet and a pen were set at each place before the participants arrived. Each participant was given 40 euros in cash at the end of the meeting.

\section{Procedure}

Once the interview chart had been drawn up, four psychologists were recruited to lead the focus groups. They had previously carried out a specific preparatory training course. To avoid any embarrassment by mixing sexes in the groups, which may have prevented the participants from expressing themselves freely on a potentially delicate subject, the women's groups were led by two female facilitators, and the men's groups were led by two male facilitators.

The focus groups were held in November 2010. On arrival, the facilitators introduced themselves and explained the purpose of the meeting. Before switching on the dictaphone, they checked that all the participants agreed to the discussion being recorded. They then gave a number of guidelines for the discussion. The topics were then introduced in turn and each participant was encouraged to give their opinion. At the end of the session, the facilitators 
summed up the meeting, collected the opinions and remarks of each participant and thanked the participants. The facilitators wrote a report after each group session.

\section{Data analysis}

The files recorded were transcribed verbatim by a professional transcriber. A general file was created, differentiating between the groups of men and women

The transcripts were then broken down to identify what each individual said in relation to the three pre-determined sub-topics, in order to create three distinct corpuses:

- Knowledge and beliefs about CRC screening;

- The facilitating factors for CRC screening using Hemoccult-II ${ }^{\circledR}$;

- The obstacles to carrying out CRC screening using Hemoccult-II ${ }^{\circledR}$.

The data were processed and analyzed using Alceste 2010 text analysis software [Alceste is a CAQDAS (Computer Aided Qualitative Data Analysis Systems) Text Analysis program]. Lexical analyses were car- ried out to identify and count the significant forms in the corpus. (In the terminology used by Alceste, form refers to a word and constitutes the base unit). Content analyses were performed to break the corpus down into significant contextual units (contextual units are chunks of words extracted from sentences or texts). Correspondence factor analyses were performed to classify the context units. Finally, cross-sectional analyses were conducted to highlight differences in discourse content between the women and the men.

\section{Results}

\section{Data description}

Analysis revealed that 3309 different words were used in the interviews, with a total word count of 40,511, covering 179 pages. Each form was used on average 12 times, with a maximum of 1376 times; 1612 words were used only once (Hapax are items that occur only once in the corpus).

\section{Knowledge and beliefs about colorectal cancer screening}

\section{Correspondence factor analysis}

This analysis revealed the factor structure of the texts concerning general knowledge and beliefs about the Hemoccult-II ${ }^{\circledR}$ screening test. $67 \%$ of Elementary Contextual Units (ECUs) were classified [ECUs are composed of several consecutive Segments of Calibrated Text. ECUs are the base statistical units of Alceste, the aim being to classify ECUs based on the distribution of vocabulary. N.B. The end of text segments are shown here by $\$$ ].

The factor structure revealed three stable categories (Figure 1A). Category 1 included 146 ECUs, corresponding to $38 \%$ of all the ECUs classified with 32 analyzed words, and concerned the advantages of colonoscopy compared to the Hemoccult-II ${ }^{\circledR}$ test. Category 2 was composed of 134 ECUs, corresponding to $34 \%$ of all the ECUs classified with 29 analyzed words. It concerned the use of the word screening associated with the principle of prevention. Category 3 comprised 109 ECUs, correspon-

Table 1. Socio-demographic characteristics of participants.

\begin{tabular}{lccccccc} 
& & \multicolumn{2}{c}{$\begin{array}{c}\text { living environment } \\
\text { Mean age (SD) }\end{array}$} & Urban & Rural & $\begin{array}{c}\text { Past history of cancer } \\
\text { Yes }\end{array}$ & \multicolumn{3}{c}{$\begin{array}{c}\text { Family history of cancer } \\
\text { Nes }\end{array}$} \\
Women & $59.47(5.6)$ & 36 & 2 & 7 & 31 & 26 & 12 \\
Men & $62.22(6.56)$ & 29 & 2 & 3 & 28 & 14 & 17 \\
\hline Total & $60.71(6.16)$ & 65 & 4 & 10 & 59 & 40 & 29 \\
\hline
\end{tabular}

$\mathrm{SD}$, standard deviation.

Table 2. Past use of Hemoccult-II ${ }^{\circledR}$ associated with future intention to carry out the test.

\begin{tabular}{|c|c|c|c|c|c|c|}
\hline & & & \multicolumn{4}{|c|}{ Past use of Hemoccult-II® } \\
\hline & & & & & & \\
\hline & & & $\begin{array}{l}\text { Women } \\
\text { (\% total) }\end{array}$ & $\begin{array}{c}\text { Men } \\
(\% \text { total) }\end{array}$ & $\begin{array}{l}\text { Women } \\
\text { (\% total) }\end{array}$ & $\begin{array}{c}\text { Men } \\
\text { (\% total) }\end{array}$ \\
\hline \multirow[t]{2}{*}{ Intention to use Hemoccult-II ${ }^{\circledR}$} & Yes & $\begin{array}{l}\text { Women } \\
\text { Men }\end{array}$ & $31(44.9)$ & $29(42.0)$ & $2(2.9)$ & $1(1.4)$ \\
\hline & No & $\begin{array}{l}\text { Women } \\
\text { Men }\end{array}$ & $2(2.9)$ & $1(1.4)$ & $3(4.3)$ & 0 \\
\hline
\end{tabular}

Table 3. Main topics and questions.

\begin{tabular}{|c|c|}
\hline Themes & Examples of questions \\
\hline Knowledge and beliefs about colorectal cancer screening & $\begin{array}{l}\text { What is a screening method? What is the purpose of carrying out a screening test? } \\
\text { What is colorectal cancer? } \\
\text { What do you know about the screening methods for colorectal cancer? }\end{array}$ \\
\hline Facilitators of colorectal cancer screening by Hemoccult-II ${ }^{\circledR}$ & $\begin{array}{l}\text { What could make you carry out a colorectal cancer screening test? } \\
\text { What made you carry out a colorectal cancer screening test? }\end{array}$ \\
\hline Barriers of colorectal cancer screening by Hemoccult-II® & $\begin{array}{l}\text { What could stop you carrying out a colorectal cancer screening test? } \\
\text { What stopped you carrying out a colorectal cancer screening test? }\end{array}$ \\
\hline
\end{tabular}


ding to $28 \%$ of all the ECUs classified with 28 analyzed words, and concerned the procedure for carrying out the Hemoccult-II ${ }^{\circledR}$ test. Examples are shown in Table 4.

\section{Cross-sectional analysis}

We performed a cross-sectional analysis of the content of the discussions about general knowledge and beliefs about CRC screening with Hemoccult-II ${ }^{\circledR}$ by sex. The women stressed the fact that colonoscopy is currently performed under anesthetic, either general or local. They used the word test (examen in French) more than the men did, and talked more about the need to detect the disease as early as possible. Men used the word prevention more than women did, and talked more about the procedure of the Hemoccult-II ${ }^{\circledR}$ test. Examples of utterances are given in Table 4.

\section{Facilitators of colorectal cancer screening by Hemoccult-II ${ }^{\circledR}$}

\section{Correspondence factor analysis}

This analysis revealed the factor structure of the discourse relating to the facilitators of using the Hemoccult-II ${ }^{\circledR}$ test. $72 \%$ of ECUs were classified.

The factor structure revealed three stable categories (Figure 1B). Category 1 comprised 141 ECUs, corresponding to $29 \%$ of all the ECUs classified with 34 analyzed words. It concerned the importance of information about the Hemoccult-II ${ }^{\circledR}$ test to motivate people to use it. Category 2 comprised 155 ECUs, corresponding to $32 \%$ of all the ECUs classified with 26 words. It concerned the simplicity of the Hemoccult-II ${ }^{\circledR}$ test procedure. Category 3 comprised 194 ECUs, corresponding to $39 \%$ of all the ECUs classified with 35 words. It concerned the impact of personal andor family history of cancer on awareness of the importance of screening. Examples of utterances are provided in Table 4.

\section{Cross-sectional analysis}

We carried out a cross-sectional analysis of the utterances regarding the facilitators of the CRC screening test by sex. The women were more influenced by the advice of their GP. They also said that they regularly tried to persuade their husbands to carry out the Hemoccult-II ${ }^{\circledR}$ test. The men stressed the importance of personal risk awareness. They also expressed the considerable impact of the constant efforts of people, particularly their wives, to persuade them to carry out the test. Examples of utterances are given in Table 4.

\section{Barriers to colorectal cancer screening by Hemoccult-II ${ }^{\infty}$}

\section{Correspondence factor analysis}

This analysis revealed the factor structure of the utterances concerning the barriers to
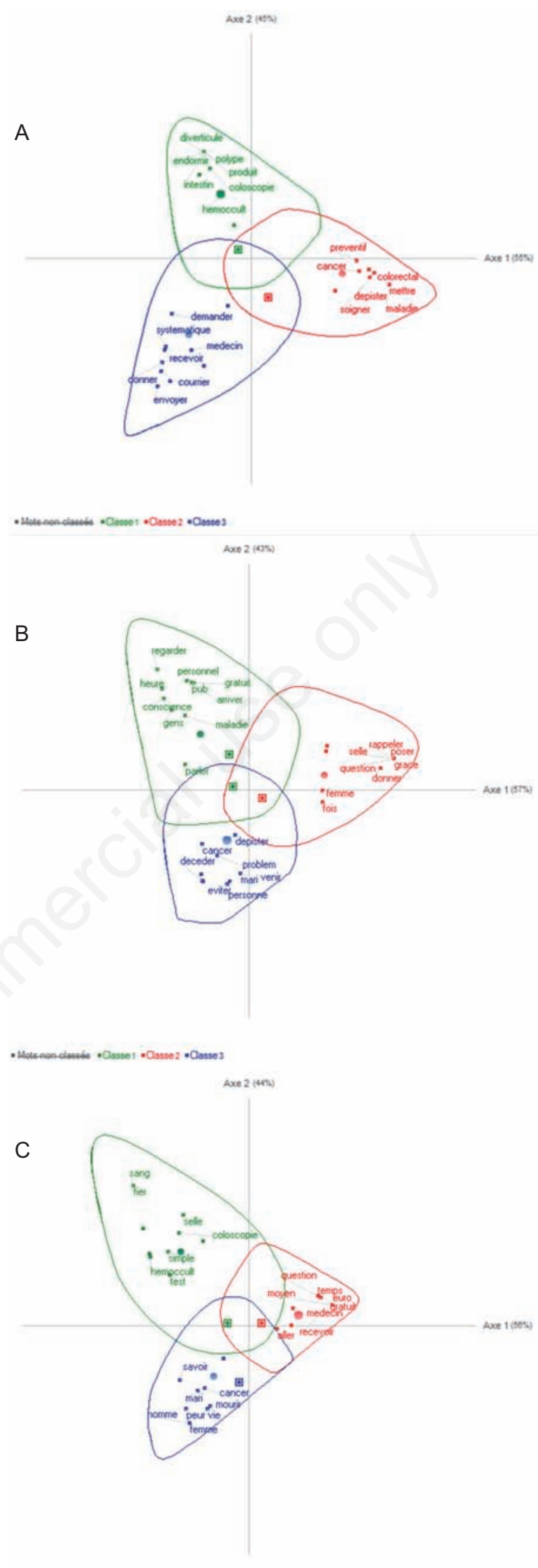

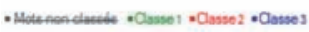

Figure 1. Results of correspondence factor analyses. A) Knowledge and beliefs about colorectal cancer screening; B) Facilitators of colorectal cancer screening by Hemoccult-II ${ }^{\circledR}$; C) Barriers to colorectal cancer screening by Hemoccult-II ${ }^{\circledR}$. 
using the Hemoccult-II ${ }^{\circledR}$ test; $80 \%$ of ECUs were classified.

The factor structure revealed three stable categories (Figure 1C). Category 1 comprised 101 ECUs, corresponding to $20 \%$ of all the ECUs classified with 28 analyzed words. It concerned uncertainty about the reliability of the Hemoccult-II ${ }^{\circledR}$ test. Category 2 comprised 231 ECUs, corresponding to $46 \%$ of all the ECUs classified with 41 analyzed words, and concerned socio-economic barriers. Category 3 comprised 173 ECUs, corresponding to $34 \%$ of all the ECUs classified with 34 analyzed words. It concerned health anxiety. Examples of utterances are shown in Table 4.

\section{Cross-sectional analysis}

We performed a cross-sectional analysis of utterances concerning barriers to using the CRC screening test by sex. The women gave greater emphasis to the inconvenience and/or embarrassment of carrying out the HemoccultII ${ }^{\circledR}$ test, a topic that some still considered taboo. The men gave greater emphasis to the fear of finding the disease to explain their lack of enthusiasm for carrying out the test. Examples of utterances are given in Table 4.

Table 4. Examples of utterances by topic.

\begin{tabular}{|c|c|c|c|}
\hline Theme & Analysis & Class & Examples of utterances \\
\hline \multirow[t]{5}{*}{$\begin{array}{l}\text { Knowledge and beliefs } \\
\text { about colorectal cancer } \\
\text { screening }\end{array}$} & \multirow[t]{3}{*}{$\begin{array}{l}\text { Correspondence } \\
\text { factor analysis }\end{array}$} & 1 & $\begin{array}{l}\text { When you get the letter about the Hemoccult test, it says that if you've had a } \\
\text { colonoscopy within the last five years you don't have to do the Hemoccult test. } \\
\text { So I think that the colonoscopy has greater value. }\end{array}$ \\
\hline & & 2 & $\begin{array}{l}\text { It's better to prevent than to cure. I think that's the expression. It certainly costs less } \\
\text { to screen from the start and to treat early than to have to treat a disease that's been } \\
\text { established for a long time and the strength of the treatment it will need. }\end{array}$ \\
\hline & & 3 & $\begin{array}{l}\text { The first time I got the letter, he gave me that and then he didn't ask me anything } \\
\text { about it and didn't encourage me to do it. }\end{array}$ \\
\hline & \multirow[t]{2}{*}{$\begin{array}{l}\text { Cross-sectional } \\
\text { analysis }\end{array}$} & 1 & $\begin{array}{l}\text { I was asleep, I prefer that. } \\
\text { It's a test you have to do every two years by taking a stool sample. }\end{array}$ \\
\hline & & 2 & $\begin{array}{l}\text { It's not much fun, but you have to go to the doctor. } \\
\text { While I like the word prevention, the word screening bothers me. It's not that it } \\
\text { bothers me, but you assume that there's something there and that it's just a question } \\
\text { of finding it. }\end{array}$ \\
\hline \multirow{5}{*}{$\begin{array}{l}\text { Facilitators of colorectal } \\
\text { cancer screening by } \\
\text { Hemoccult-II }{ }^{\circledR}\end{array}$} & \multirow[t]{3}{*}{$\begin{array}{l}\text { Correspondence } \\
\text { factor analysis }\end{array}$} & 1 & $\begin{array}{l}\text { People talk about it now. People who've had cancer, people who are afraid of having it } \\
\text { can talk about it. }\end{array}$ \\
\hline & & 2 & $\begin{array}{l}\text { Yes, of course I've talked to my GP about it and he encouraged me to do it. } \\
\text { No, I didn't find this test particularly difficult to use. It's true that when you're retired } \\
\text { you have fewer constraints than young people who work. } \\
\text { Hang on, there are a lot worse things in my opinion. }\end{array}$ \\
\hline & & 3 & $\begin{array}{l}\text { Because my dad died of colon cancer. My maternal grand-mother breast cancer, a } \\
\text { cousin a brain tumor. I don't know if that's considered as cancer, but they're things } \\
\text { that made an impression on me. }\end{array}$ \\
\hline & \multirow[t]{2}{*}{$\begin{array}{l}\text { Cross-sectional } \\
\text { analysis }\end{array}$} & 1 & $\begin{array}{l}\text { I did it because things weren't working properly. My doctor advised me to do it, } \\
\text { so much that I encouraged my husband to do it too, and my doctor said carry on } \\
\text { because I've just been declared positive and fortunately I'd done it! }\end{array}$ \\
\hline & & 2 & $\begin{array}{l}\text { It seems to me that women are naturally more inclined to be interested, to worry } \\
\text { about the health now or in the future of their family, the children, the husband. }\end{array}$ \\
\hline \multirow[t]{3}{*}{$\begin{array}{l}\text { Barriers to colorectal } \\
\text { cancer screening by } \\
\text { Hemoccult-II }{ }^{\circledR}\end{array}$} & \multirow[t]{3}{*}{$\begin{array}{l}\text { Correspondence } \\
\text { factor analysis }\end{array}$} & 1 & $\begin{array}{l}\text { It's what I said at the beginning, I've heard that the Hemoccult-II test, the one I've } \\
\text { done for about ten years, the results aren't very reliable. } \\
\text { I wondered how reliable it is, so it's true that I had a colonoscopy because I was a bit } \\
\text { bothered. I did it because I wasn't at all sure about the test. }\end{array}$ \\
\hline & & 2 & $\begin{array}{l}\text { So it's better to wait, not answer. That way you get the envelope and you don't need to } \\
\text { go to the doctor. }\end{array}$ \\
\hline & & 3 & $\begin{array}{l}\text { Lots of men refuse to look facts in the face I think. Lots of men are afraid of disease, } \\
\text { isn't that right? } \\
\text { It's a bit frightening. It frightens me. All forms of cancer. } \\
\text { I'm also really afraid of being in the } 3 \% \text { and that they tell me. I'd prefer that they didn't } \\
\text { tell me and that they treat me. } \\
\text { I watch the letter box every day. I admit I'm a very anxious person. I feel really } \\
\text { stressed, but once I've put my test in the post. }\end{array}$ \\
\hline \multirow[t]{2}{*}{$\begin{array}{l}\text { Barriers to colorectal } \\
\text { cancer screening by } \\
\text { Hemoccult-II }{ }^{\circledR}\end{array}$} & \multirow[t]{2}{*}{$\begin{array}{l}\text { Cross-sectional } \\
\text { analysis }\end{array}$} & 1 & $\begin{array}{l}\text { You know, it's not something you're going to keep for pleasure... } \\
\text { You're all alone, all alone in the toilet, telling yourself you've got to wait, you're not } \\
\text { given much help, you don't really know, you read..... } \\
\text { And that someone else, excuse the expression, was going to sniff my shit... I was } \\
\text { terribly embarrassed for the person who was going to receive it. }\end{array}$ \\
\hline & & 2 & $\begin{array}{l}\text { Breast and colorectal cancer, you feel there isn't the same message about them. I } \\
\text { think that in addition to the GP who should also play a part in prevention, there should } \\
\text { be appropriate publicity to tell you about the issue. } \\
\text { They can't say cancer: it's shocking. }\end{array}$ \\
\hline
\end{tabular}




\section{Discussion}

\section{Knowledge and beliefs about colorectal cancer screening}

The idea that colonoscopy is a more reliable test than the Hemoccult-II ${ }^{\circledR}$ test to detect CRC emerged in all the focus groups. Participants considered that colonoscopy was more reliable in that it is more likely to detect cancerous tumors. Greiner et al. ${ }^{25}$ reported similar positive attitudes towards colonoscopy. In spite of an invasive, inconvenient and embarrassing procedure, the participants endorsed colonoscopy for its reliability compared to the Hemoccult-II ${ }^{\circledR}$ test, whose sensitivity is currently under debate. ${ }^{23}$

Moreover, colonoscopy is a passive procedure for the patient because it is carried out under anesthetic by an experienced gastroenterologist. By contrast, the Hemoccult-II ${ }^{\circledR}$ test is carried out by the individual, who takes on an active role, with the possible fear of not performing it correctly and thereby invalidating it. This aspect has been highlighted by Coronado et al. ${ }^{9}$ who found that individuals do not have confidence in a medical test which is not performed by a doctor who is familiar with the procedure. In short, people doubt their ability to carry out the test properly. ${ }^{7}$

The discussions highlighted many aspects of the participants' understanding of the notion of screening. They defined screening in general as a means of looking for and detecting the signs of a given pathology. They stressed particularly the early detection of cancer, believing that this would avoid its anarchic and rapid development, late and difficult treatment, and potentially fatal outcome. This finding appears to support the idea that people recognize the importance of early screening, 14 whether or not they carry out the test, and whether or not they have doubts about its reliability and efficacy.

The large majority of the participants in this study had already performed the HemoccultII ${ }^{\circledR}$ test at least once, and thus had relatively good knowledge about its procedure. Nevertheless, there were a few uncertainties and disagreements, probably due to the fact that the participants had used different versions of the test and that the procedures themselves have changed and improved over time (colorectal cancer screening was initiated in France in 2003). Several authors have found similar confusion regarding the instructions provided with the test kit.7,21

The women particularly appeared to favor the colonoscopy procedure which is currently performed under general or local anesthetic. Some women appreciated this aspect in that it prevents any pain and suffering induced by the procedure. Anesthesia also prevents the embarrassment caused by exposing certain parts of the body and the unseemly posture adopted during the test.

As mentioned above, women were more likely than men to use the word test (examen in French) to describe CRC screening tests. In the medical context, the word refers to an attentive and in-depth observation of what is happening inside the body, and also the clinical and technical investigations carried out by health professionals to determine an individual's state of health. The women were probably reassured by the serious connotation of the word, which stresses the reliability of the procedure.

The men used the word prevention more than the women did. This word covers all the prophylactic measures undertaken to protect against certain risks and diseases. Based on this definition, we hypothesize that the men tended to prefer the word prevention to screening because they attributed a more fatalistic meaning to the word screening, while prevention fostered the hope of never being affected by the disease.

The men were more voluble than the women when discussing the procedure of the Hemoccult-II ${ }^{\circledR}$ test. They readily admitted their reticence to consult a doctor and to discuss certain sensitive subjects about intimate parts of the body, CRC screening being one of the most difficult subjects for them to raise with a doctor. 29

\section{Facilitators of colorectal cancer screening by Hemoccult-II ${ }^{\circledR}$}

All the participants stressed the importance of information about screening to encourage people to take the test regularly. They were convinced that efforts made to raise awareness about CRC and screening are worthwhile, in particular by making the topic less taboo and thus easier to discuss, and also because health professionals have now set up the media support needed to raise public awareness. By contrast, most studies highlight the lack of information and media interest in CRC screening, ${ }^{30}$ focusing more on the difficulty of discussing CRC screening with others because it is still considered a shameful subject. ${ }^{17}$ The results of our study suggest that this topic is easier to discuss in France, perhaps due to specific cultural values and/or the major efforts that have been made by public health organisations to convey the message (we refer here for example to Mars Bleu, an annual colorectal cancer awareness event held every March to raise public awareness of the risks of this disease and to encourage people to undergo a screening test). Nevertheless, it seems that the people who are best informed are generally those who have already carried out the test at least once, ${ }^{14}$ which was the case for most of the participants in our study.

Moreover, our participants considered in general that the Hemoccult-II ${ }^{\circledR}$ test is relative- ly simple to perform with no particular problems, at least compared to other similar types of medical procedures. Even if it can be initially laborious, they see it as a question of adapting to this new procedure so that it becomes normal. This finding confirms those of several authors who found that Hemoccult-II ${ }^{\circledR}$ is seen as a convenient and relatively simple test to use. ${ }^{31}$ When the test has been done once, it probably appears easier and less threatening. ${ }^{14}$

It should also be noted that the people we questioned were more interested in CRC screening when they themselves had a personal andor family history of cancer, which supports data in the literature. ${ }^{31}$ Knowing someone with cancer, and having first-hand experience of cancer (colorectal or other), personifies the disease and raises awareness of the negative impact of cancer both on daily life and on life expectancy. This type of experience has a lasting effect on the perception of screening and health behavior in general, making them seem reassuring by distancing the potential risks. Agreeing to a screening test is thus motivated mainly by the hope of detecting a potential tumor at an early stage, reducing the risk of an early death, and avoiding the anxiety and worry of the prospect of having a CRC. 15

It is also clear that the women paid more attention to the advice of their GP and were more readily influenced by it. They confided more readily in their GP, which could explain why they followed their advice more than the men did. This finding is in line with the study by Holmes-Rovner et al.13 who observed that women are generally better informed about the goals of screening because they are more likely to talk about it with their GP.

The women also stated that they regularly tried to persuade their husbands to carry out the Hemoccult-II ${ }^{\circledR}$ test, taking on a protective role towards members of the household. They regularly brought up the subject to try to overcome their husbands' reticence and encourage them one way or another to do the test. It is noteworthy that whatever the cultural background of the participants in different studies, women always find it easier to discuss CRC screening, 17 and it is generally they who persuade close family or friends to carry out a screening test. 16

The men seemed to confirm that their wives played a significant role in their decision to do the test. The fact that men bestow a maternal role on their wives, who are seen to take care of the family as a whole, suggests that women could play a useful role in disseminating information. 16

\section{Barriers to colorectal cancer screening by Hemoccult-II ${ }^{\circledR}$}

The statements collected in our study show the uncertainty and suspicion regarding the reliability of the Hemoccult-II ${ }^{\circledR}$ test. The par- 
ticipants expressed surprise at the lack of sensitivity of the test, raising doubts about the reliability of the results and suggesting that it is pointless when there are other more efficient tests. A false positive result tends to produce temporary but profound anxiety, while a false negative result puts at risk people who wrongly think they have no problem. This observation should be seen alongside studies that criticize the lack of sensitivity of guaiac tests and recommend the use of immunological faecal occult blood tests (in France, CRC screening is free or completely refunded by Social Security. However, to obtain the screening kit, some people have to go to their GP and pay for the consultation, although this is refunded. People with a complementary health insurance scheme are generally refunded the full cost of the consultation, less one euro. By contrast, people with no complementary health insurance scheme, by choice or necessity, are only refunded the proportion covered by Social Security, i.e. $70 \%$ of the cost of the consultation). These studies seem to have a certain impact on the general public who sense the doubts held by some doctors regarding the Hemoccult-II ${ }^{\circledR}$ test. $^{23}$

Participants could feel concerned at a personal level or by solidarity and sympathy towards people who are hesitant about doing the screening test, potentially jeopardizing their health due to financial considerations. This is not surprising in view of the many studies that have highlighted the economic barriers to the screening procedure.10,11 However, as the test is free in France and health care costs are refunded, we did not expect this criterion to play such an important role and constitute such a major barrier for the participants in our study.

Finally, a high level of health anxiety seems to play a role in failure to undergo a CRC screening test or in carrying it out late. More precisely, the participants expressed their fear of discovering that they had CRC through the Hemoccult-II ${ }^{\circledR}$ test. The men expressed more anxiety than the women, giving it as a reason for their lack of willingness to do the test. They also expressed their apprehension about cancer, one of the most anxiogenic diseases; the mere mention of the word, over and above its consequences, can generate marked anxiety. The participants also expressed their fear of the repercussions of the cancer, which is liable to generate a certain amount of pain and considerable unpleasantness. The fear of discovering a cancer through screening is a recurring theme among the participants of many studies.6,25 However, we believe that it is important to identify more precisely the nature of the fears experienced by people when they are invited to carry out a CRC screening test and that the concept of health anxiety will lead to a better understanding of this phenomenon.
The women stressed the disgust and/or embarrassment of carrying out the HemoccultII ${ }^{\circledR}$ test more than men. Many were repulsed by handling their faeces or storing the kit. Some expressed their embarrassment about having to send the kit to the laboratory by post, knowing that the packet contained samples of their faeces, destined to be analyzed by a total stranger whose job they did not envy. Several other studies have found that people frequently describe the test as repugnant, disgusting and unhealthy, ${ }^{24}$ due notably to the disgust and embarrassment of handling, collecting and storing faeces. ${ }^{7}$

For their part, the men insisted more on the current lack of information about CRC, compared to other types of cancer which are given a higher media profile and are better known by the general public. They also said that they were less used to screening procedures than women who regularly go for exclusively feminine screening tests (mammograms and cervical smears). Holt et al. ${ }^{16}$ also found that some men consider that there is less media coverage about CRC than about other cancers, notably those that affect women. They tend to see this as an injustice, an indication that their health is of less interest than that of women.

Finally, this study has a number of methodological biases limiting the generalization of its findings, which should be interpreted with the usual caution. First, the way the focus group participants were recruited did not enable us to have a completely representative sample of the population targeted for CRC screening. In fact, all the participants were readers of a specific regional daily newspaper which had published an article which erroneously stated that the researchers were looking for people who had already been screened.

Generally, focus groups attract people who are assertive and who are willing to express their opinion in public. The methodology can lead individuals to be influenced by other members of the group and possibly feel obliged to conform to the social norms of the group. The limited size of the sample, which is normal for this type of study, is also a potential obstacle to generalizing the results.

Moreover, the majority of participants declared that they participated to CRC screening at least once. This type of study attracts people who are very interested or who feel personally concerned by the subject of the discussion. Yet it is exactly the persons who participate most to CRC screening.

With regard to the interpretation of the data, the results of the cross-sectional analyses should be interpreted with caution. They should be seen in relation to the actual situation of the focus group, which assumes that there is an interaction between the participants. It is thus difficult to be sure of any real difference with regard to the use of a given word, even if this bias was relatively minimized by the number of groups.

\section{Conclusions}

The aim of this qualitative study was to explore both the main barriers and the facilitating factors for undergoing a CRC screening test in a sample of the French population. The main results highlight a certain number of beliefs and attitudes towards CRC screening and seem to corroborate a considerable amount of data from similar studies conducted in other countries.

Overall, the notion of screening seemed to be relatively well understood and accepted by the participants, who commented on the awareness campaigns set up to inform the general public about the importance of CRC screening. They were generally convinced of the importance of screening, due to the clear benefit of early detection of cancerous tumors, with better treatment and a higher survival rate. Personal and/or family history of any type of cancer is very probably involved in the decision to undergo screening, as suggested by our interviewees. Screening would help prevent experiencing or re-experiencing the unpleasantness and pain of the disease, and possibly death. It should also be noted that the women were clearly more sensitive to media campaigns than men and to the advice of their GP regarding early detection, which could explain why they put more effort into the screening procedure, both for themselves and for their close relatives. The men seemed to confirm the persuasive role of their wives who actively encouraged them to take the test, while acknowledging their own awareness of their physical vulnerability and their responsibility for their own health.

Nevertheless, the value of the HemoccultII ${ }^{\circledR}$ test was clearly not recognized by all the participants due to the many questions regarding its reliability. Many of the participants felt that it is a second-rate test, inferior to a colonoscopy which is deemed to be considerably more effective at detecting polyps and cancerous tumors. The Hemoccult-II ${ }^{\circledR}$ test is also criticized for the confusion about how to obtain it (via the GP), its cost (medical consultation), its procedure (simple but with a number of inconveniences) and the perceived lack of medical follow-up. The Hemoccult-II ${ }^{\circledR}$ test is also considered to be embarrassing to use, in spite of the acknowledged fact that there are now fewer related taboos. The fear of being diagnosed with cancer following a simple medical test also constitutes a real barrier to CRC screening. People seem to be more afraid of receiving the news that they have $\mathrm{CRC}$ than of the disease itself, in spite of its alarming 
nature, and thus put off doing the test.

Finally, this preliminary exploratory study provides valuable and detailed data on a topic. To our knowledge, it is the first study of its kind to be carried out among the general public in France. The results help us to understand better the psychological determinants of a failure to screen people with an average risk of developing CRC. Eventually we hope that these data could help health organizations and professionals develop better CRC screening campaigns with a view to reducing the death rate caused by late treatment of the disease.

\section{References}

1. Bouvier AM. Epidémiologie descriptive du cancer colorectal en France. BEH 2009;23:14-6.

2. Bouvier AM, Chauvenet M, Jooste V, Faivre J. Le poids du cancer colorectal en France en 2005: estimation de sa prévalence et du nombre de patients nécessitant des soins. BEH 2010;12:105-8.

3. Faivre J, Lepage C, Dancourt V. Le dépistage organisé du cancer colorectal en France et en Europe: historique et état des lieux. BEH 2009;2-3:17-9.

4. Blay JY, Eisinger F, Rixe 0, et al. Le programme Edifice: analyse des pratiques de dépistage du cancer en France. Bull Cancer 2008;95:1067-73.

5. Garcia M, Borràs J, Diaz-Milà N, et al. Factors associated with initial participation in a population-based screening for colorectal cancer in Catalonia, Spain: a mixed-methods study. Prev Med 2011;52: 265-7.

6. Goldsmith G, Chiaro C. Colorectal cancer screening: how to help patients comply. J Fam Pract 2008;57:2-7.

7. Jones R, Devers K, Kuzel AW. Patientreported barriers to colorectal cancer screening: A mixed-methods analysis. Am J Prev Med 2010;38:508-16.

8. Varela A, Jandorf L, DuHamel K. Understanding factors related to colorectal cancer (CRC) screening among urban Hispanics: use of focus group methodology. J Cancer Educ 2010;25:70-5.

9. Coronado G, Farias A, Thompson B, et al. Attitudes and beliefs about colorectal cancer among mexican americans in commu- nities along the US-Mexico border. Ethn Dis 2006;16:421-7.

10. Fyffe D, Hudson S, Fagan J, Brown D. Knowledge and barriers related to prostate and colorectal cancer prevention in underserved black men. J Natl Med Assoc 2008; 100:1161-7.

11. Goel V, Gray R, Chart P, et al. Perspectives on colorectal cancer screening: a focus group study. Health Expectations 2004;7:51-60.

12. Natale-Pereira A, Marks J, Vega M, et al. Barriers and facilitators for colorectal cancer screening practices in the Latino community: perspectives from community leaders. Cancer Control 2008;15:157-65.

13. Holmes-Rovner M, Williams G, Hoppough $\mathrm{S}$, et al. Colorectal cancer screening barriers in persons with low income. Cancer Pract 2002;10:240-7.

14. Bauerle Bass S, Gordon T, Burt Ruzek S, et al. Perceptions of colorectal cancer screening in urban African American clinic patients: differences by gender and screening status. J Cancer Educ 2011;26: 121-8.

15. Rawl S, Menon U, Champion V, et al. Colorectal cancer screening beliefs: focus groups with first-degree relatives. Cancer Pract 2000;8:32-7.

16. Holt C, Shipp M, Eloubeidi M, et al. Use of focus group data to develop recommendations for demographically segmented colorectal cancer educational strategies. Health Educ Res 2009;24:876-89.

17. Beeker C, Kraft J, Southwell B, Jorgensen C. Colorectal cancer screening in older men and women qualitative research findings and implications for interventions. $\mathrm{J}$ Commun Health 2000;25:263-78.

18. O'Sullivan I, Orbell S. Self-sampling in screening to reduce mortality from colorectal cancer: a qualitative exploration of the decision to complete a faecal occult blood test (FOBT). J Med Screen 2004;11: 16-22.

19. Royak-Schaler R, Blocker D, Yali A, et al. Breast and colorectal cancer risk communication approaches with low-income African-American and Hispanic women: implications for healthcare providers. J Natl Med Assoc 2004;96:598-608.

20. Friedemann-Sanchez G, Griffin J, Partin M. Gender differences in colorectal cancer screening barriers and information needs. Health Expectations 2006;10:148-60.
21. Brouse C, Basch C, Wolf R, et al. Barriers to colorectal cancer screning with fecal occult blood testing in a predominantly minority urban population: a qualitative study. Am J Public Health 2003;93:1268-71.

22. Weitzman E, Zapka J, Estabrook B, Goins K. Risk and reluctance: understanding impediments to colorectal cancer screening. Prev Med 2001;32:502-13.

23. Katz M, Heaner S, Reiter $P$, et al. Development of an educational video to improve patient knowledge and communication with their healthcare providers about colorectal cancer screening. Am J Health Educ 2009;40:220-8.

24. Clavarino A, Janda M, Hughes K, et al. The view from two sides: a qualitative study of community and medical perspectives on screening for colorectal cancer using FOBT. Prev Med 2004;39:482-90.

25. Greiner K, Born W, Nollen N, Ahluwalia J. Knowledge and perceptions of colorectal cancer screening among urban african americans. J Gen Intern Med 2005;20:97783.

26. Harris M, Treloar C, Byles J. Colorectal cancer screening: discussions with first degree relatives. Aust NZ J Public Health 1998;22:826-8.

27. Aubin-Auger I, Mercier A, BaumannCoblentz T, et al. Identifier les obstacles au dépistage du cancer colorectal et envisager les moyens de les surmonter. Hemobstacle: une étude qualitative. Exercer 2008;19:4-7.

28. Ingrand I, Dujoncquoy S, Beauchant M, et al. General practitioner and specialist wiews on colonoscopic screening of firstdegree relatives of colorectal cancer patients. Cancer Epidemiol 2009;33:22330.

29. Dubé C, Fuller B, Rosen R, et al. Men's experiences of physical exams and cancer screening tests: a qualitative study. Prev Med 2005;40:628-35.

30. MacKenzie R, Chapman S, McGeechan K, Holding S. A disease many people still feel uncomfortable talking about: Australian television coverage of colorectal cancer. Psychooncology 2010;19:238-88.

31. Feeley T, Cooper J, Foels T, Mahoney M. Efficacy expectations for colorectal cancer screening in primary care: identifying barriers and facilitators for patients and clinicians. J Health Communic 2009;24:304-15. 